Stability of vitamin E in wheat flour and whole wheat flour during storage

Engelsen, Merete Møller; Hansen, Åse Solvej

Published in:

Cereal Chemistry

DOI:

10.1094/CCHEM-85-6-0716

Publication date:

2008

Document version

Publisher's PDF, also known as Version of record

Citation for published version $(A P A)$ :

Engelsen, M. M., \& Hansen, A. S. (2008). Stability of vitamin $E$ in wheat flour and whole wheat flour during storage. Cereal Chemistry, 85(6), 716-720. https://doi.org/10.1094/CCHEM-85-6-0716 


\title{
Stability of Vitamin E in Wheat Flour and Whole Wheat Flour During Storage
}

\author{
Merete Møller Nielsen ${ }^{1}$ and Åse Hansen ${ }^{1,2}$
}

\section{ABSTRACT}

Cereal Chem. 85(6):716-720

The stability of vitamin E during 297 days of storage of wheat flour and whole wheat flour ground on a stone mill or a roller mill, respectively, were studied. One day after milling, the total content of vitamin E, expressed in vitamin E equivalents $(\alpha$-TE), was $18.7 \alpha$-TE and $10.8 \alpha$-TE for stone-milled and roller-milled wheat flour, respectively. The difference in total vitamin $\mathrm{E}$ content was primarily due to the absence of the germ and bran fractions in the roller-milled flour. The total loss of vitamin E during storage was $24 \%$ for stone-milled wheat flour but $50 \%$ for roller-milled wheat flour. These results indicate that vitamin E, which is present in high amounts in wheat germ, functions as an antioxidant in the stone-milled wheat flour. Hexanal formation showed that lipid oxidation in roller-milled flour occurred just after milling, whereas the formation of hexanal in the germ fraction displayed a lack period of 22 days, confirming that vitamin $\mathrm{E}$ functions as an effective antioxidant in the wheat germ. Results showed no significant difference in total loss of vitamin E for stone-milled and roller-milled whole wheat flour. Total loss after 297 days of storage for both milling methods was $\approx 32 \%$.
Naturally occurring vitamin $\mathrm{E}$ is an important antioxidant in foods. It is composed of eight isomers: four tocopherols $(\alpha-\mathrm{T}, \beta$ $\mathrm{T}, \gamma-\mathrm{T}$, and $\delta-\mathrm{T})$ and four tocotrienols $(\alpha-\mathrm{T} 3, \beta-\mathrm{T} 3, \gamma-\mathrm{T} 3$, and $\delta$ T3). Cereal grains, together with vegetable oils, are good sources of vitamin $E$ (Franke et al 2007). Wheat grains contain $\alpha-T, \beta-T$, $\alpha-\mathrm{T} 3$, and $\beta$-T3; the $\alpha-\mathrm{T}$ and $\beta$-T content is an average of 16 times higher in the germ than in the bran fractions, whereas the $\alpha$ $\mathrm{T} 3$ and $\beta$-T3 content is approximately twice as high in the bran fractions compared with the germ fraction (Barnes 1983; Piironen et al 1986; Nielsen and Hansen, unpublished). The level of vitamin $\mathrm{E}$ in milled wheat products depends on the extraction rate of the flour, but other factors like milling method, breadmaking, and storage might also influence the vitamin $\mathrm{E}$ content in the flour to be used by consumers and the baking industry.

Commercial milling is done using either roller mills or stone mills. Roller milling is the principal commercial milling method because it has a very high capacity. Roller milling is done on break rolls, sizing rolls, and reduction rolls. The objective of the breaking system is to break open the wheat grain, remove the endosperm and germ from the bran coat, and gradually grind the practically pure endosperm into flour. A stone mill is the oldest mill used for grinding wheat, wherein the grinding action occurs between two mill stones (disks). The principle in stone milling is the use of the forces of compression, shear, and abrasion (Posner 2005). The grains are fed into the center of the top stone, which is rotated while the bottom stone remains stationary. The grains are broken and ground by flutings in the stones, and the material is discharged by the rotating stone through an outlet. Separation in both systems is done using sifters and purifiers (Bass 1988; Posner 2005). The main difference between the two methods is that in stone milling it is not possible to separate the germ from the endosperm.

Vitamin E can function as an antioxidant for unsaturated fatty acids (UFA) in wheat flour to prevent rancidity (Slover and Lehmann 1972; Kamal-Eldin and Appelqvist 1996). In wheat, the total content of lipids is $2-3 \%$ and $\approx 63 \%$ of the lipids are located in the endosperm, 34\% in the germ, and 3\% in the pericarp/bran (Chung 1991). The dominant UFA in wheat are palmitic acid $(2 \%)$, oleic acid $(15 \%)$, linoleic acid $(58 \%)$, and linolenic acid (4\%) (Chung 1991; Hoseney 1994). The wheat lipids oxidize during storage; however, the oxidation might be inhibited by the vitamin E. Whole wheat flour (extraction rate 100\%) might oxi-

\footnotetext{
${ }^{1}$ University of Copenhagen, Faculty of LIFE Sciences, Dept Food Science, Quality \& Technology, Rolighedsvej 30, DK-1958 Frederiksberg C, Denmark.

${ }^{2}$ Corresponding author. E-mail: aah@life.ku.dk
}

doi:10.1094/CCHEM-85-6-0716

(C) 2008 AACC International, Inc. dize more rapidly than wheat flour with a 70-75\% extraction rate because bran fractions and the lipid-rich germ still are present in whole wheat flour. Germ and bran fractions are also rich in enzymes influencing the oxidation, such as lipase and lipoxygenase.

Lipid oxidation can be divided into three types: autoxidation, photooxidation, and enzymatic oxidation. Autoxidation occurs when unsaturated fatty acids like oleic acid, linoleic acid, and linolenic acid are exposed to oxygen (Belitz et al 2004). Secondary oxidation forms products like ketones and aldehydes. Photooxidation is accelerated by light exposure; the presence of photosensitizers forms secondary oxidation products as in autoxidation (Nawar 1996; Frankel 2005). The last type of oxidation is enzymatic oxidation which is initiated by certain enzymes. Lipoxygenase (LOX) (EC 1.13.11.12) is present in many plants and catalyzes the oxidation of some polyunsaturated fatty acids (Gardner 1988). Because LOX is specific to UFA with a cis,cis 1,4pentadien system, linoleic and linolenic acids will oxide easily in the presence of LOX (Belitz et al 2004). Experiments with wheat flour showed that LOX activity is relatively high in flours where the germ and bran are maintained together with the endosperm (Rani et al 2001). This is due to the fact that both the bran and the germ are rich in LOX. Wheat germ and wheat bran have $17 x$ and $4 \times$, respectively, as much LOX activity as is present in the endosperm (Rani et al 2001). Prooxidants and antioxidants can affect the rate of oxidation and vitamin $\mathrm{E}$, like an antioxidant, can inhibit or retard the oxidation (Angelo 1996). Lipid oxidation is often quantified in terms of volatile secondary lipid oxidation products. Hexanal is an oxidation product present in large amounts and it has been used often to indicate lipid oxidation (Fritsch and Gale 1977; Frankel 2005). Hexanal is a good indicator of the degree of oxidation and, along with other volatiles like 1-octen-3-one, pentanal, and 2(E)-nonanal, hexanal has been applied in various products to follow the quality deterioration (Ullrich and Grosch 1987; Jensen and Risbo 2007).

The purpose of this study was to determine whether the stability of vitamin E during storage of whole wheat flour and wheat flour depended on the milling method used. The aim was also to investigate how quickly the oxidation of the UFA takes place during storage of high- and low-extraction wheat flour and wheat germ by monitoring the lipoxygenase activity and the development of hexanal.

\section{MATERIALS AND METHODS}

The storage experiment took place in two time periods. The first period was to determine whether the milling method (roller milling or stone milling) had an effect on the vitamin E stability of the milled products. The second period was to investigate how 
the decrease in vitamin E content was related to lipid oxidation by measuring the activity of lipoxygenase and the development of hexanal.

\section{Grain and Flour Samples}

Organic whole wheat flour (WWF) (extraction rate $\approx 100 \%$ ) and wheat flour (WF) (extraction rate $\approx 70 \%$ ) were obtained from two Danish mills, one using roller mills (RM) and one using stone mills (SM), in June 2005 for the first experiment. Whole wheat grains, wheat flour, and wheat germ (WG) were obtained from the Danish mill using roller mills in September 2006 for the second experiment. All samples were kept in paper bags normally used for commercial household packaging of flour and stored at room temperature in darkness for up to 297 days. Immediately before analysis, the samples were milled to a particle size of $0.5 \mathrm{~mm}$ in the laboratory using a Udy cyclone sample mill.

\section{Dry Matter Content}

The dry matter content was determined in duplicate using the gravimetric method by oven drying $\left(130^{\circ} \mathrm{C}\right.$ and $\left.90 \mathrm{~min}\right)$ according to ICC standard method No. 110/1.

\section{Determination of Tocopherol and Tocotrienol Contents}

Tocopherol and tocotrienol contents in the samples were measured by a method of Nielsen and Hansen (unpublished). Using this procedure, $1 \mathrm{~g}$ of milled sample was extracted with $30 \mathrm{~mL}$ of hexane and placed in an ultrasound bath for $10 \mathrm{~min}$. The supernatant was evaporated to dryness under nitrogen and dissolved in $3 \mathrm{~mL}$ of hexane and filtered through a $0.45-\mu \mathrm{m}$ filter. All extracts were made in triplicate. The quantitative HPLC separation was performed on a LiChrosorb Si $60(125 \times 4 \mathrm{~mm}$ i.d., particle size 5 $\mu \mathrm{m})$ normal-phase column protected with a steel guard column (50 $\times 3 \mathrm{~mm}$ i.d., particle size $5 \mu \mathrm{m}$ ) filled with ChromGuard S (Bie and Berntsen, Copenhagen, Denmark). The temperature of the column oven was $25^{\circ} \mathrm{C}$. The mobile phase contained a solution of hexane, ethyl acetate, and acetic acid (94.6:3.6:1.8) and the flow rate of the mobile phase was set at $1.0 \mathrm{~mL} / \mathrm{min}$ (Nielsen and Hansen 2008). The tocopherols and tocotrienols were identified by retention time and quantified by use of linear regression from a calibration curve for all eight isomers $(1-25 \mu \mathrm{g} / \mathrm{mL})$. For the first part of the experiment, the vitamin E content was measured after $1,7,16,37,94,187$, and 297 days in both the RM and SM samples. For the second part of the experiment, the vitamin E content was measured after 1, 7, 15, 22, 54, and 224 days in RM samples. Total equivalents of vitamin $\mathrm{E}$ (TE) were calculated as $\alpha-\mathrm{TE} / \mathrm{g}$, $\mathrm{dm}=\left(\alpha-\mathrm{T}^{*} 1.0\right)+\left(\beta-\mathrm{T}^{*} 0.5\right)+(\alpha-\mathrm{T} 3 * 0.3)+(\beta-\mathrm{T} 3 * 0.05)$.

\section{Lipoxygenase Assay}

To measure the LOX activity, $5 \mathrm{~g}$ of sample was blended with $40 \mathrm{~mL}$ of potassium phosphate buffer $(50 \mathrm{~m} M, \mathrm{pH} 7.0$, added $0.1 \%$ Triton-X) by Ultra-Turrax. The extract was centrifuged for $30 \mathrm{~min}$ at $3,000 \mathrm{rpm}$ and $0^{\circ} \mathrm{C}$, filtered, and kept on ice until the analysis. Lipoxygenase in the enzyme extract was measured in a continuous assay by measuring consumption of initial oxygen by an oxygen-sensitive probe (YSI 5010 BOD probe) with a dissolved oxygen meter (YSI 5100) at $30^{\circ} \mathrm{C}$ using linoleic acid as a substrate. Calibration was done at $30^{\circ} \mathrm{C}$ by air-saturated tempered phosphate buffer $\left(0.2 \mathrm{M}, \mathrm{pH} 6.0,21 \%\right.$ dissolved $\left.\mathrm{O}_{2}\right)$ followed by addition of sodium dithionite $\left(0 \%\right.$ dissolved $\left.\mathrm{O}_{2}\right)$.

To determine LOX activity, $27.2 \mathrm{~mL}$ of air-saturated phosphate buffer and $3.9 \mathrm{~mL}$ of enzyme extract were mixed in a $33-\mathrm{mL}$ conical flask and then measured. After $30 \mathrm{sec}$, the reaction was initiated by adding $1.9 \mathrm{~mL}$ of sodium linoleate solution $(10 \mathrm{mM})$. The level of $\mathrm{O}_{2}$ was monitored over 20 min, measuring $\mathrm{O}_{2}$ content once every second. To determine the activity of LOX, the $\mathrm{O}_{2}$ level (mmol of $\mathrm{O}_{2}$ ) was plotted against time, and the steepest slope ( $\mathrm{mmol}$ of $\mathrm{O}_{2} / \mathrm{sec}$ ) on the curve was found using a continuous linear regression over $20 \mathrm{sec}$ at a time. Blank samples were run on buffer-added substrate and enzyme extract. The samples were made in duplicate and measured after 1, 8, 17, 23, and 224 days of storage.

\section{Isolation and Quantification of Hexanal}

Dynamic headspace was used to isolate volatile compounds, especially hexanal. In the latter, hexanal is used as an indicator of lipid oxidation and is thus the main compound to be considered. Sample $(20 \mathrm{~g})$ was weighed in a 250 -mL glass flask equipped with a purge head. The sample was then placed in a water bath at $30^{\circ} \mathrm{C}$ and purged with nitrogen $(100 \mathrm{~mL} / \mathrm{min})$ for $1 \mathrm{hr}$. Hexanal and other volatiles were collected on traps containing $250 \mathrm{mg}$ of Tenax-TA material (mesh size 60/80, Buchem bv, Apeldorn, The Netherlands). The samples were then subjected to automated thermal desorption (ATD) and gas chromatography and mass spectroscopy (GC-MS) analysis. Dynamic headspace collections were made in duplicate and measured after 1, 8, 17, 23, and 224 days of storage. The collected volatiles were thermally desorbed using an automated thermal desorption device (ATD 400, Perkin Elmer). Desorption time from the trap to the cold trap was $15 \mathrm{~min}$ at $250^{\circ} \mathrm{C}$, with a helium flow of $60 \mathrm{~mL} / \mathrm{min}$. Volatiles were desorbed from the cold trap to the GC-column by flash heating from 5 to $300^{\circ} \mathrm{C}$.

Separation and identification of aroma compounds were conducted on a GC-MS system (Hewlett-Packard G1800A) equipped with a DB-Wax column (J\&W Scientific, $30 \mathrm{~m} \times 0.25 \mathrm{~mm} \times 0.25$ $\mu \mathrm{m})$ using helium as the carrier gas $(1 \mathrm{~mL} / \mathrm{min})$. The column temperature was kept at $45^{\circ} \mathrm{C}$ for $10 \mathrm{~min}$ and then increased by $6^{\circ} \mathrm{C} / \mathrm{min}$ to $240^{\circ} \mathrm{C}$, and kept there for $10 \mathrm{~min}$. The mass selective detector used the electron ionization mode accumulating 15-300 $\mathrm{m} / \mathrm{z}$ scan. Identification and quantification was done by probabilitybased matching with mass spectra in the Wiley Library (HewlettPackard) and relative areas were given.

\section{Statistical Analyses}

Data were presented in Table I as the mean \pm SD. Differences between vitamin $\mathrm{E}$ isomers, flour type, milling method, and time were determined using ANOVAN, an $n$-way analysis of the samples, and were run in MATLAB 7.1 software. Differences with $P$ $<0.05$ were considered significant.

\section{RESULTS AND DISCUSSION}

\section{Vitamin E During Storage}

The results from the first storage experiment, in which the vitamin E content was analyzed during storage of RM and SM flour samples is shown in Fig. 1 and Table I. The total amount of vitamin E, expressed in total equivalents of vitamin E (TE) is shown in Fig. 1. The SM WWF (A) and the RM WWF (B) contained similar levels of vitamin $\mathrm{E}$ throughout the whole storage period of 297 days.

The content of vitamin $\mathrm{E}$ in the WF depends on the milling method used, and the content of vitamin $\mathrm{E}$ is much lower in the RM WF due to the composition of the flour. WF from RM does not contain germ or bran fractions and because different isomers of vitamin $\mathrm{E}$ are primarily located in the germ and bran fractions, it was to be expected that the RM WF contained a lower total content of vitamin E (Barnes 1983). For both milling methods, a significant decrease in vitamin E content occurred after 94 days of storage.

The total loss of vitamin E during 297 days of storage was $50 \%$ for RM WF and $31 \%$ for RM WWF. These observations are in agreement with the experiments performed by Wennermark and Jagerstad (1992), who measured a loss of $40 \%$ for WWF and 38\% for WF, but after 12 months of storage. There was no significant difference between SM WF and WWF, and the total loss was determined to be $\approx 34 \%$. 
TABLE I

Vitamin E Content in Whole Wheat Flour (WWF) and Wheat Flour (WF) Milled on Either a Stone Mill or on a Roller Mill (RM) During 297 Days of Storage

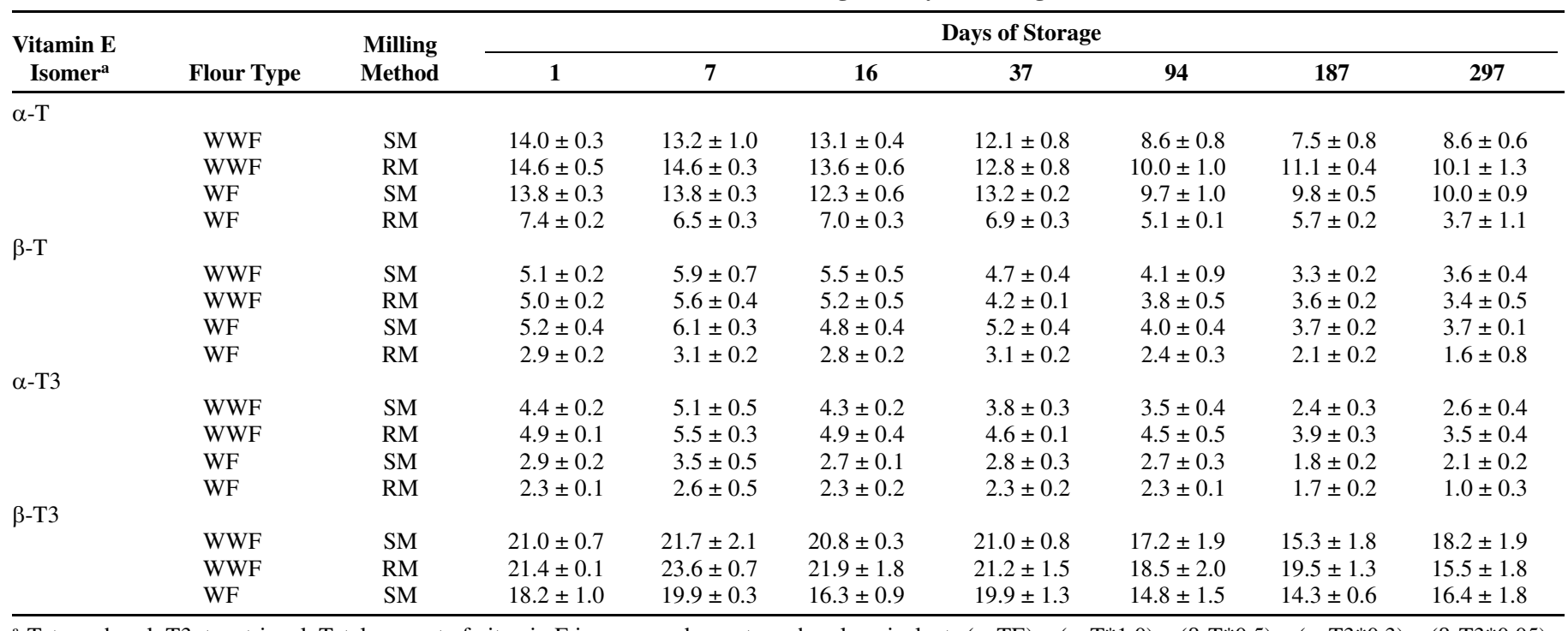

a $\mathrm{T}$, tocopherol; T3, tocotrienol. Total amount of vitamin $\mathrm{E}$ is expressed as $\alpha$-tocopherol equivalents $(\alpha-\mathrm{TE})=(\alpha-\mathrm{T} * 1.0)+(\beta-\mathrm{T} * 0.5)+(\alpha-\mathrm{T} 3 * 0.3)+(\beta-\mathrm{T} 3 * 0.05)$.

In Table I, the content of four different isomers is listed for two types of flour (WWF and WF) and two types of milling methods (SM and RM) over 297 days of storage. The content of $\beta$-T3 is highest in all samples, followed by the content of $\alpha-$ T. $\alpha$-T3 and $\beta$-T are approximately at the same low level.

The loss of $\alpha$-T in RM WWF was $\approx 31 \%$ during storage, whereas the SM WWF loss was $\approx 36 \%$ of the $\alpha$-T. No difference in milling method was observed for $\beta$-T, as total loss was $\approx 31 \%$ in SM WWF, which was not significantly lower than the loss of $32 \%$ for RM WWF. The loss of $\beta$-T3 was also independent of milling method, probably due to the fact that the $\beta-\mathrm{T} 3$ is more equally distributed in the bran and endosperm than the typical germ isomer $\alpha$-T (Barnes 1983).

The tocopherols are primarily located in the germ, and a higher loss, especially of $\alpha-T$, was expected for SM WWF due to the presence of germ (Nielsen and Hansen, unpublished). $\alpha$-T3 is primarily located in the bran fractions, and the total loss proved independent of the milling method. $\beta$-T3 proved to be the most stable isomer form during the storage period of 297 days. The loss of $\beta$-T3 was most pronounced for the RM flour because roller mills separate bran fractions into several fractions and the flour is thus more exposed to air while going through the milling system before the desired fractions are collected into the final product. The storage experiment revealed no significant differences in the vitamin E content and storage stability of WWF flour between the two milling methods. Only differences due to extraction rates ( 70 vs. $100 \%$ ) were revealed for RM flour.

\section{Lipoxygenase Activity and Formation of Hexanal During Storage of Wheat Germ and Flour}

The second storage experiment investigated lipid oxidation by using RM samples because this milling method produces almost pure fractions of wheat germ (WG) and wheat flour (WF). This experiment was performed to investigate the relationship between the loss of vitamin E during storage and lipid oxidation, and thus to investigate whether vitamin $\mathrm{E}$ functions as an antioxidant in the wheat flour during storage. Lipid oxidation was monitored by measuring the lipoxygenase activity and the oxidative stability of the flour, which was simultaneously followed by the development of hexanal.

In Fig. 2A, the $\alpha$-T content in milled wheat grains, wheat flour, and wheat germ is plotted using two axes because the amount of $\alpha-T$ in the wheat germ (right axis) was an order of magnitude
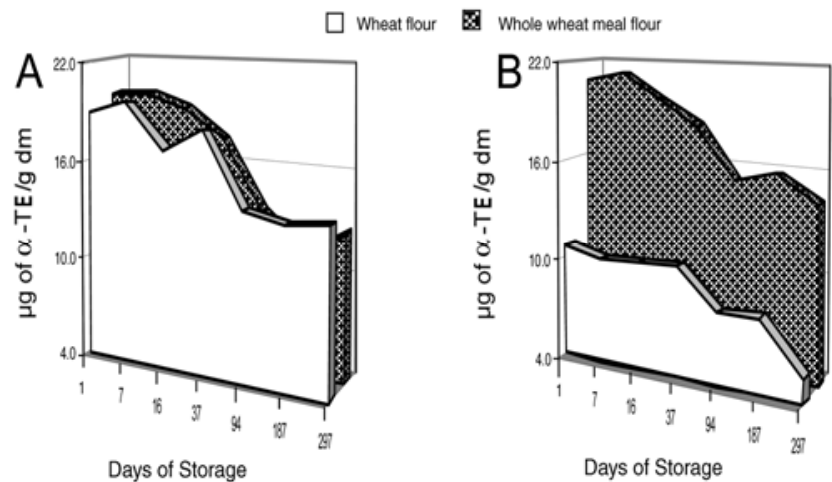

Fig. 1. Total content of vitamin $\mathrm{E}(\mu \mathrm{g}$ of $\alpha-\mathrm{TE} / \mathrm{g}, \mathrm{dm})$ in stone-milled flours (A) and roller-milled flours (B). $\alpha$-Tocopherol equivalents $(\alpha-\mathrm{TE})$ are calculated as $\left(\alpha-\mathrm{T}^{*} 1.0\right)+\left(\beta-\mathrm{T}^{*} 0.5\right)+(\alpha-\mathrm{T} 3 * 0.3)+(\beta-\mathrm{T} 3 * 0.05)$.

higher than the grains and flour (left axis). From Fig. 2, it is clear that the pattern of $\alpha-T$ degradation is the same for all three samples. We also note that the total loss of $\alpha$-T in WF was higher in this experiment than the findings of the first part of the experiment; however, the degradation pattern remains the same.

In Fig. 2B, the activity of LOX is plotted as a function of storage time. The milled wheat grains display a higher level of LOX activity compared with that of the wheat flour. This is explained by the fact that the grains are freshly milled before analysis and still contain both germ and bran. Previous studies have shown that the activity of LOX in bran fractions is much higher than in flour, and that LOX activity is highest in the germ fractions (Galliard 1986; Gökman et al 2007). Therefore, a higher LOX content in the milled wheat grains compared with WF was expected.

The LOX activity in the WWF decreased throughout the storage period. In contrast, the LOX activity in WF increased slightly during the first month of storage to remain stable throughout the remaining storage period. This was expected because the bran and germ fractions were removed, resulting in a low lipids content $(<1 \%)$ (Nielsen and Hansen, unpublished) and enzymes; hence there was limited lipid oxidation. In contrast, the LOX activity in WG increases to the highest activity after 37 days, from which point the activity decreases rapidly. As lipase is located in the bran and LOX is primarily located in the germ (Galliard 1983), it was expected that the LOX activity would be highest in the pure 

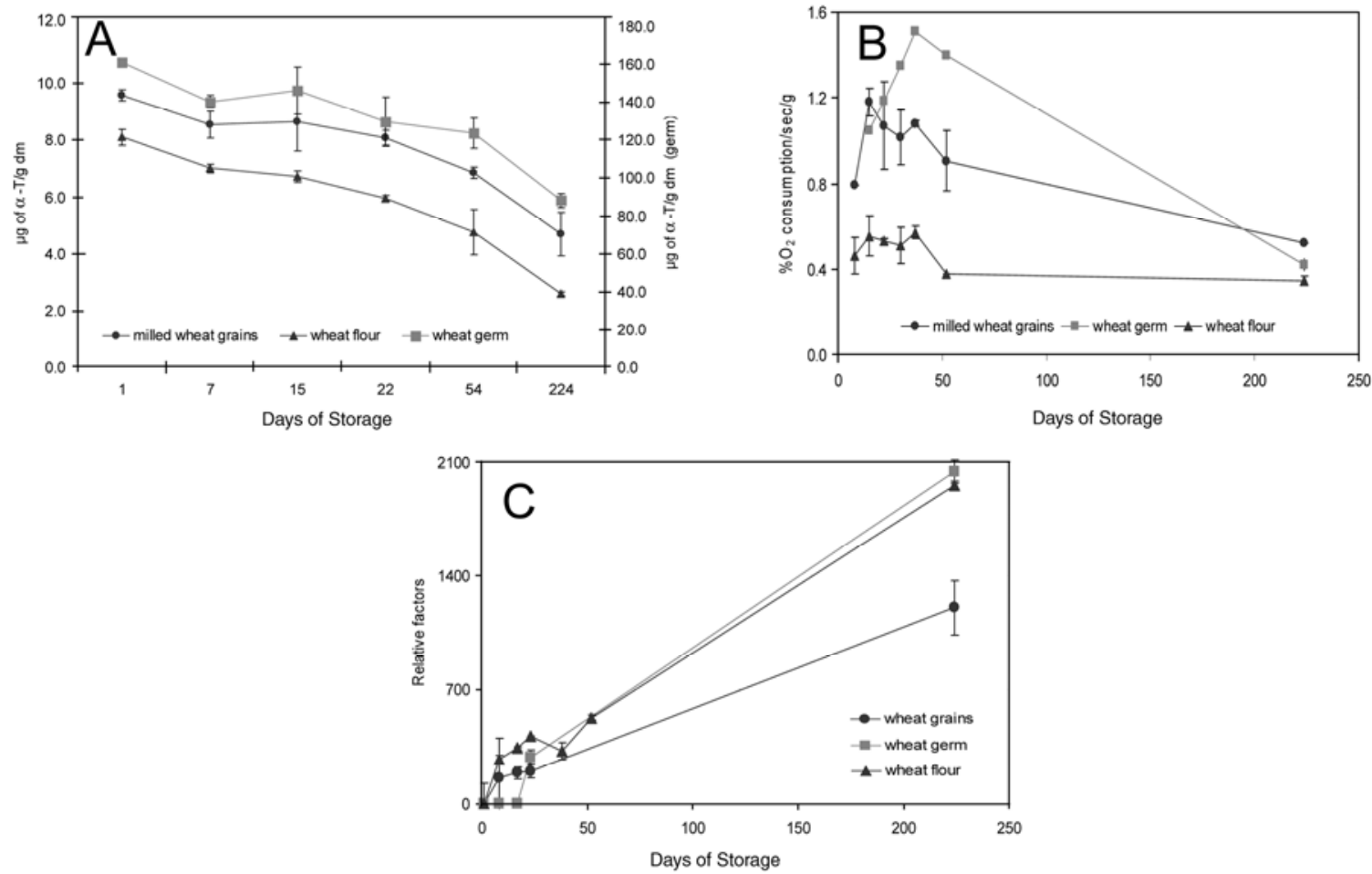

Fig. 2. A, Content of $\alpha-\mathrm{T}$ in milled wheat grains, roller-milled wheat flour, and wheat germ during 224 days of storage. B, Lipoxygenase activity expressed as $\% \mathrm{O}_{2}$ consumption/sec/g in milled wheat grains, roller-milled wheat flour, and wheat germ during 224 days of storage. C, Development of hexanal during 224 days of storage of milled wheat grains, wheat flour, and wheat germ fraction from roller milling.

germ fraction. Indeed, the result from monitoring LOX activity as a function of storage time showed a high LOX activity in the germ and in the milled wheat grains and a lower activity in the wheat flour, meaning that some lipid oxidation occurs in wheat flour during storage.

Using formation of hexanal as an indicator of lipid oxidation, Fig. 2C shows that the level of hexanal increases in all samples throughout the whole storage period. The increase in hexanal formation is smaller for milled wheat grains compared with WF and WG. After 224 days of storage, the amount of hexanal in the wheat grains was $\approx 50 \%$ of the amount in WG and WF while, as expected, the hexanal formation in WF increases throughout the whole storage period. Apparently the formation of hexanal was not correlated to LOX activity. This result is in good agreement with other experiments, which show that oxidation products are produced immediately after milling of the whole wheat flour, and that the amount of oxidation products increases linearly with time during storage at $20^{\circ} \mathrm{C}$ (Galliard 1986; Tait and Galliard 1988). Oxidation in WG has a lag period of 17 days before the formation of hexanal becomes measurable, which means that vitamin $\mathrm{E}$, and especially $\alpha-T$ in this intermediate storage period, functions as an effective antioxidant with the ability to suppress lipid oxidation.

\section{CONCLUSIONS}

A significant difference in the content of vitamin $\mathrm{E}$ between SM and RM WF was observed. The highest content was measured in SM WF. The difference in content was ascribed to the lack of germ and bran fractions in RM WF. The total loss of vitamin E in wheat flour was $24 \%$ for SM WF but $50 \%$ for RM WF during the storage period, indicating that vitamin $\mathrm{E}$ in the germ functions as an antioxidant in the SM WF. The results of this study also show that lipid oxidation in RM flour, expressed as hexanal formation, occurred immediately after milling, whereas the formation of hexanal in the germ fraction had a lag period of 22 days, confirming that vitamin $\mathrm{E}$ functions as an effective anti- oxidant in wheat germ. LOX displayed highest activity in the germ fraction, followed by milled whole grains and wheat flour, respectively. The results in this study showed that no significant differences between the two milling methods were observed at the end of a storage period for WWF.

\section{ACKNOWLEDGMENTS}

We want to thank laboratory technician Mehdi Farahani for assistance with the HPLC equipment, associate professor Frans van den Berg for the statistical analysis in MATLAB 7.1, and Gilda Kischinovsky for proofreading this manuscript. We acknowledge Valsemøllen A/S and Aurion $\mathrm{A} / \mathrm{S}$ for providing the samples. This study was financed by DFFE and SOAR.

\section{LITERATURE CITED}

Angelo, A. J. 1996. Lipid oxidation of foods. Crit. Rev. Food Sci. Nutr. 36:175-224.

Barnes, P. J., ed. 1983. Non-saponificable lipids in cereals. Pages 33-53 in: Lipids in Cereal Technology. Academic Press: London.

Bass, E. J. 1988. Wheat flour milling. Pages 1-68 in: Wheat: Chemistry and Technology. Y. Pomeranz, ed. AACC International: St. Paul, MN.

Belitz, H.-D., Grosch, W., and Schieberle, P. 2004. Lipids. Pages 157-244 in: Food Chemistry. Springer-Verlag: Berlin.

Chung, O. K. 1991. Cereal lipids. Pages 497-554 in: Handbook of Cereal Science and Technology. K. J. Lorenz and K. Kulp, eds. Marcel Dekker: New York.

Franke, A. A., Murphy, S. P., Lacey, R., and Custer, L. J. 2007. Tocopherol and tocotrienol levels of foods consumed in Hawaii. J. Agric. Food. Chem. 55:769-778.

Frankel, E. N. 2005. Lipid Oxidation, 2nd Ed. Oily Press: Bridgwater, England.

Fritsch, C. W., and Gale, J. A. 1977. Hexanal as a measure of rancidity in low fat foods. J. Am. Oil Chem. Soc. 54:225-228.

Galliard, T. 1983. Enzymatic degradation of cereal lipids. Pages 111-147 in: Lipids in Cereal Technology. P. J. Barnes, ed. Academic Press: New York.

Galliard, T. 1986. Hydrolytic and oxidative degradation of lipids during storage of wholemeal flour: Effects of bran and germ components. J. 
Cereal Sci. 4:179-192.

Gardner, H. W. 1988. Lipoxygenase pathway in cereals. Pages 161-215 in: Advances in Cereal Science and Technology. Y. Pomeranz, ed. AACC International: St. Paul, MN.

Gökman, V., Serpen, A., Atli, A., and Köksel, H. 2007. A practical spectrophotometric approach for the determination of lipoxygenase activity of durum wheat. Cereal Chem. 84:290-293.

Hoseney, R. C., ed. 1994. Minor constituents. Pages 81-102 in: Principles of Cereal Science and Technology. AACC International: St. Paul, MN.

Jensen, P. N. and Risbo, J. 2007. Oxidative stability of snack and cereal products in relation to moisture sorption. Food Chem. 103:717-724.

Kamal-Eldin, A., and Appelqvist, L.-A. 1996. The chemistry and antioxidant properties of tocopherols and tocotrienols. Lipids 31:671-701.

Nawar, W. W. 1996. Lipids. Pages 225-320 in: Food Chemistry. O. R. Fennema, ed. Marcel Dekker: New York.

Nielsen, M. M., and Hansen, A. 2008. Rapid high-performance liquid chromatography (HPLC) determination of tocopherols and tocotrienols in cereals. Cereal Chem. 85:248-251.
Piironen, V., Syvaoja, E. L., Varo, P., Salminen, K., and Koivistoinen, P. 1986. Tocopherols and tocotrienols in cereal products from Finland. Cereal Chem. 63:78-81.

Posner, E. S. 2005. The grinding process. Pages 185-221 in: Wheat Flour Milling. E. S. Posner and A. N. Hibbs, eds. AACC International: St. Paul, MN.

Rani, K. U., Prasada Rao, U. J. S., Leelavathi, K., and Haridas Rao, P. 2001. Distribution of enzymes in wheat flour mill streams. J. Cereal Sci. 34:233-242.

Slover, H. T., and Lehmann, J. 1972. Effects of fumigation on wheat in storage. IV. Tocopherols. Cereal Chem. 49:412.

Tait, S. P. C., and Galliard, T. 1988. Effect on baking quality of changes in lipid composition during wholemeal storage. J. Cereal Sci. 8:125-137.

Ullrich, F., and Grosch, W. 1987. Identification of the most intense volatile flavour compounds formed during autoxidation of linoleic acid. Zeit. Lebensm. Unters. Forschung 184:277-282.

Wennermark, B., and Jagerstad, M. 1992. Breadmaking and storage of various wheat fractions affect vitamin E. J. Food Sci. 57:1205-1209.

[Received November 20, 2007. Accepted February 26, 2008.] 